\title{
CONGENITAL TOXOPLASMOSIS IN THE NEWBORN
}

\author{
BY \\ E. G. HALL, J. D. HAY, P. D. MOSS and M. M. P. RYAN \\ From the Mill Road Maternity Hospital and the Department of Child Health, the University, Liverpool
}

(RECEIVED FOR PUBLICATION NOVEMBER 12, 1952)

A majority of the recorded cases of congenital toxoplasmosis have shown either clinical evidence of damage to the central nervous system at birth or have developed such signs after the first few weeks of life. The purpose of this report is to describe two cases, occurring within a short period in one maternity unit, showing at birth signs of generalized disease. One infant lived only a few minutes, the other survived for several months and developed the classical picture of hydrocephalus, chorioretinitis, microphthalmia and cerebral calcification.

\section{Case Reports}

Case 1. The mother of J.M.C., a girl, first came under medical care in 1946, when her Wassermann reaction was strongly positive. She was given a full course of treatment and subsequent Wassermann reactions were all negative. At the fifteenth week of her first pregnancy in August, 1949 , a precautionary course of 'novarsenobillon' and bismuth was started. After three injections penicillin was substituted for the arsenical, because of bleeding from the gums. A blood count at that time was normal. There was no history of any illness suggesting toxoplasma infection during or immediately preceding pregnancy. For the two months before delivery there was marked hydramnios. Labour occurred on February 9, 1950, a low forceps extraction being performed owing to foetal distress. The placenta weighed $740 \mathrm{~g}$. $(1 \mathrm{lb} .10 \mathrm{oz}$.) and was of normal appearance.

The infant weighed $2,730 \mathrm{~g}$. (6 lb.) and was $48 \mathrm{~cm}$. (19 inches) long. Her condition at birth was fairly good and she improved rapidly after aspiration of meconium from the pharynx. There was a purplish rash, suggesting small, fading, recent ecchymoses, over the trunk and limbs, but not on the hands and feet. There were no true petechiae, nor were there lesions in the mouth. The liver was slightly enlarged and the spleen easily felt. The fontanelles were large, the sutures separated, and craniotabes was present. Both eyes were small, the right more so than the left. No other abnormalities were noted.

Ten hours after birth the rash was more pronounced and there was slight jaundice. On the second day the rash had faded considerably, the jaundice had become very deep, and the fontanelle tension had increased. On the fourth day the liver was larger and hydrocephalus was evident. Ophthalmological examination by Mr. J. A. McCann confirmed the microphthalmia, the right cornea being $6 \mathrm{~mm}$. in diameter: there were extensive haemorrhagic masses in the vitreous. The left cornea was $8 \mathrm{~mm}$. in diameter and there was a vitreous mass on this side also. Radiographs of the skull on February 12 and on February 23 showed multiple discrete foci of calcification arranged in linear streaks and scattered throughout the hemispheres (Fig. 1). They were most marked in the frontal area and in the region of the basal nuclei. Early hydrocephalus was present. Radiographs of the long bones, lungs and abdomen were normal.

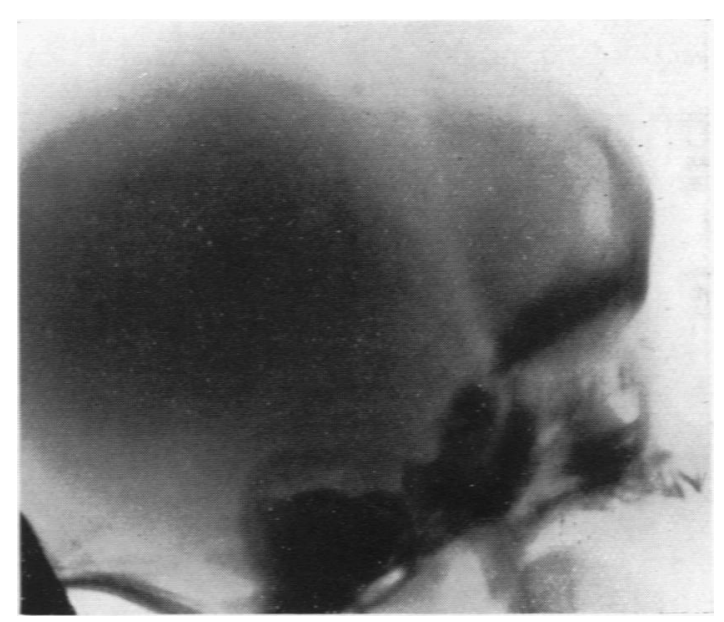

Fig. 1.-Radiograph of the skull on February 23, 1950, to show intracerebral calcification.

The rash lasted approximately two weeks and the jaundice one month. The spleen increased in size and then diminished, but, together with the liver, remained palpable for about three months. During this period the most striking clinical feature was a rapid increase in the hydrocephalus (Fig. 2). The maximum circumference of the skull at the age of 5 months was $57 \mathrm{~cm}$. (23 inches). A ventriculogram at the end of May showed an extremely thin cortex and marked internal hydrocephalus with greatly dilated lateral and third ventricles (Fig. 3). Nystagmus was constantly present and the infant appeared to be blind and mentally defective. The limbs were spastic for a time, but during the fourth month she started moving them vigorously. Her condition then 
gradually deteriorated and she died on July 20, 1950. Sulphamezathine, 0.25 g., was given four-hourly for 11 days starting on March 6.

Investigations. These, on mother and infant, gave the following results:

Mother. On August 17, 1949, the blood group was $O$ IV $R$ with no $R h$ antibodies. The Kahn test was nega-

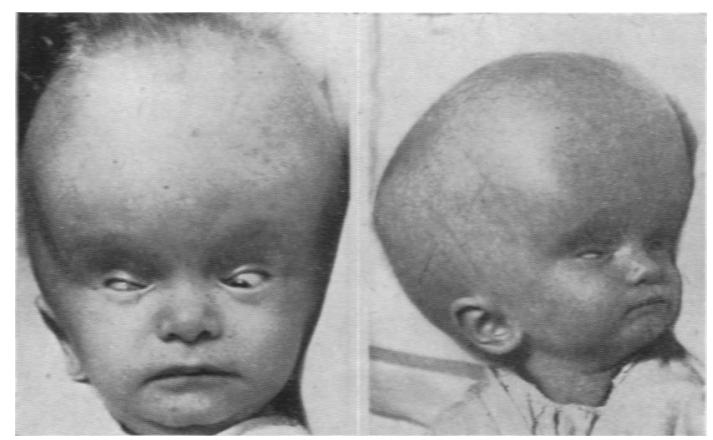

Fig. 2.-Hydrocephalus and microphthalmia: (A) on March 3, (B) on July 18 .

tive. On March 8, 1950, the indirect Coombs test was negative. On March 28 a complement fixation test for toxoplasmosis was positive in a serum dilution of 1 in $\mathbf{4 0}$. The egg neutralization test was positive. The dye test was not done.

INFANT. On February 9, 1950, a blood count gave $\mathrm{Hb}$. 18.0 g. (122\% Haldane); leucocytes 9,200 per c.mm.

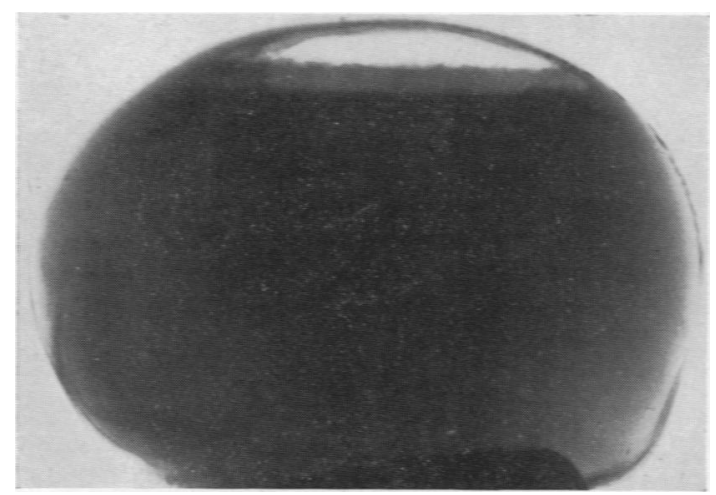

FKG. 3.-Ventriculogram taken on May 23 to show thinning of the cortex and gross dilatation of the lateral ventricles.

(differential count normal); platelets, 72,000 per c.mm.; clotting and bleeding times normal. On February 27 a complement fixation test for toxoplasmosis was positive in a serum dilution of 1 in 30 . A dye test was positive (titre $>1$ in 256).

On March 8 a blood count gave Hb. $13 \cdot 3$ g. $(90 \%$ Haldane); leucocytes 8,000 per c.mm. The differential and platelet counts were normal.
On March 9 the Wassermann reaction was negative. On March 16 a blood count gave $\mathrm{Hb} .9 .6 \mathrm{~g} .165^{\circ}$ 。 Haldane); leucocytes 8,000 per c.mm. ( $8 \%$ eosinophils).

On June 8 a complement fixation test for toxoplasmosis was positive (titre $>1$ in 1,024).

On June 22 the blood group was O IV Rh positive. On the same day a biopsy of the thigh muscle was taken. Histology was normal, and Toxoplasma was not obtained on inoculation of mice and eggs.

The cerebrospinal fluid was examined on three $\alpha$ casions between the fourth and the fifteenth week, the final fluid being obtained from the ventricles. The first and last specimens were normal, but the one taken in the ninth week contained $\mathbf{4 0}$ lymphocytes per c.mm. and had a protein content of $200 \mathrm{mg} . \%$. All three fluids were examined for Toxoplasma microscopically and by inoculation into mice and fertile eggs, but gave negative results.

In view of the suggestion that toxoplasmic infection might be transmitted to man from domestic animals, a complement fixation test was done on the serum of a cat in the mother's home, with a negative result.

Necropsy Report. (The necropsy was performed by Dr. R. E. Rewell who has kindly permitted us to quote from his report and has presented material to us.) The only changes outside the nervous system were early. bilateral basal bronchopneumonia and slight enlargement of a rather pale liver. The bones of the vault were thin and separated. The dura and subdural space were normal. The enormous enlargement of the head was due to gross internal hydrocephalus, the cerebrospinal fluid being clear and colourless. The cerebral hemispheres were reduced to a thin layer of brain, nowhere more than $5 \mathrm{~mm}$. in thickness. There were numerous areas, especially in the lateral surface of the parietal, occipital and temporal lobes, where distension was so great that the ventricular wall consisted only of a thin, translucent membrane without any gross evidence of brain tissue. The wall of the lateral ventricles was faintly granular, the choroid plexus atrophic and flattened against the thalamus. Alongside the plexus on both sides was a narrow linear zone of white calcified tissue with a smooth surface. Scattered in the cortex and the ventricular walls were scanty calcified nodules approximately $1 \mathrm{~mm}$. in diameter, occurring both singly and in small groups. The third ventricle was dilated, the fourth of normal size. The basal meninges were thickened and there was a marked tonsillar pressure cone.

Histology. Numerous sections of the spleen, pancreas. ovary, stomach, duodenum, bladder, thyroid, diaphragm. thymus, adrenal and heart were examined. The appearances were normal and no Toxoplasma were seen. The kidney was normal except for scanty small interstitial aggregates of lymphocytes in the cortex; Toxoplasma were not seen. The lungs showed an early pyogenic bronchopneumonia only and the liver was of normal pattern with light periportal fatty infiltration.

BraIN. Sections at various points in the hemispheres showed similar appearances. There were scattered cortical lesions consisting of areas of gliosis in which calcium deposits occurred as minute granules and as larger aggregates. Where these lesions reached the surface of the 


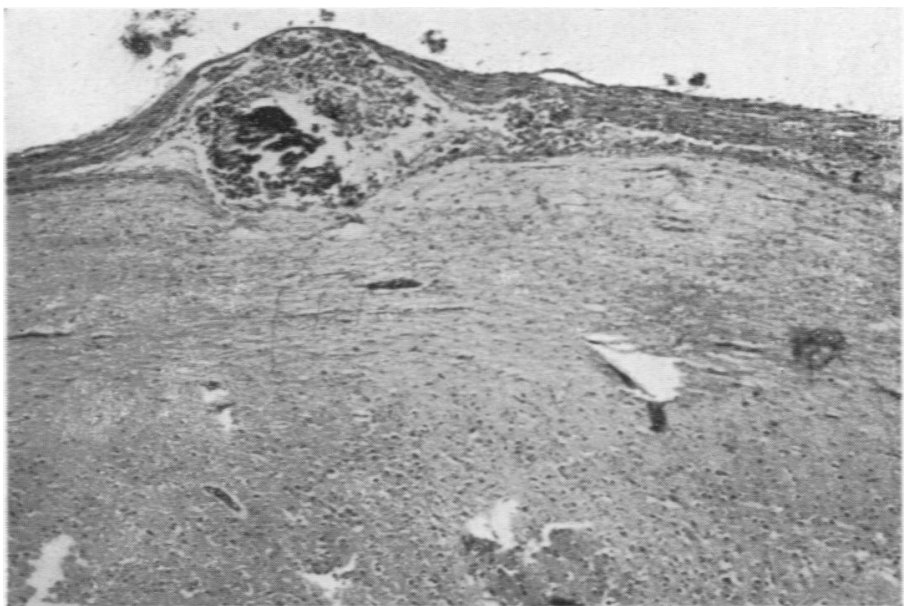

Frg. 4.-Wall of the lateral ventricle (haematoxylin and eosin $\times 40$ ) showing replacement of ependyma by glial tissue containing calcium deposits.

brain the leptomeninges were adherent and there were light perivascular aggregations of lymphocytes, monocytes and plasma cells. Frequently, however, gliosis and calcification occurred as a narrow band lying immediately beneath the surface, the overlying meninges being normal. The ependymal lining of the ventricles was replaced almost entirely by a narrow zone of compressed glia, frequently split into superficial and deep zones by microscopic calcium deposits (Fig. 4). In sections across the basal nuclei there was an almost continuous superficial zone of granular calcification, especially prominent close to the choroid plexuses where macroscopic deposits were frequent (Fig. 5). The choroid plexus of the lateral and third ventricles showed only a mild fibrosis of the stroma. Sections of the midbrain showed a normal pattern. The aqueduct in its proximal portion was dilated, and its ependyma largely intact. There were, however, small nodules of gliosis encroaching on the lumen, by-passing and isolating clumps of ependymal cells. At the level of the inferior quadrigeminal body, extensive gliosis reduced the lumen to a minute channel (Fig. 6). The fourth ventricle, cord and cerebellum were normal. Very scanty pseudocysts were seen in the brain stem.

The eyes were not available for examination.

Placenta. Two blocks were available for study. Numerous sections did not show any structural abnormality, nor were any parasites seen.

The mother of J.M.C. became pregnant again, and gave birth to a mature normal infant in August, 1951.

Case 2. The mother of Baby S. was 37 years old and had had six previous pregnancies. The eldest child died of diabetes, but the other children were well. In none had jaundice been noted during the neonatal period. The mother was first seen on November 31, 1949, at approximately 14 weeks' gestation. She gave no history of illness during or immediately before pregnancy. Her haemo- globin level was $14 \cdot 8$ g. $(100 \%$ Haldane , her blood group O IV R, and the Kahn test was negative. $R h$ antibodies were absent from her serum. When questioned later she stated that there were mice in the house, and, during the early stages of pregnancy, a cat, which had since died.

She was admitted in labour on April 23, 1950 , at 35 weeks' gestation, and delivery was normal. The placenta weighed 1,200 g. $(2 \mathrm{lb} .10 \mathrm{oz}$.) and was very pale and friable, the cut surface resembling a finemesh latex sponge.

The infant weighed $2,170 \mathrm{~g}$. $(4 \mathrm{lb} .12$ oz.) and was $42.5 \mathrm{~cm}$. (17 in.) long. He was pale, oedematous, in extremely poor condition, and died 15 minutes after delivery.

The puerperium was normal. A second Kahn test on April 25 was negative, and $\mathrm{Rh}$ antibodies were not detected. On June 8,1950 , the toxoplasmosis complement fixation test was positive in a serum dilution of 1 in 20, and the dye test titre was 1 in 256 .

A radiograph of the infant's skull, taken for reasons other than the diagnosis of toxoplasmosis, showed faint calcification in the region of the basal nuclei. As this was not seen until after the necropsy, attempts to isolate Toxoplasma were not made.

Necropsy. This was performed 14 hours after delivery

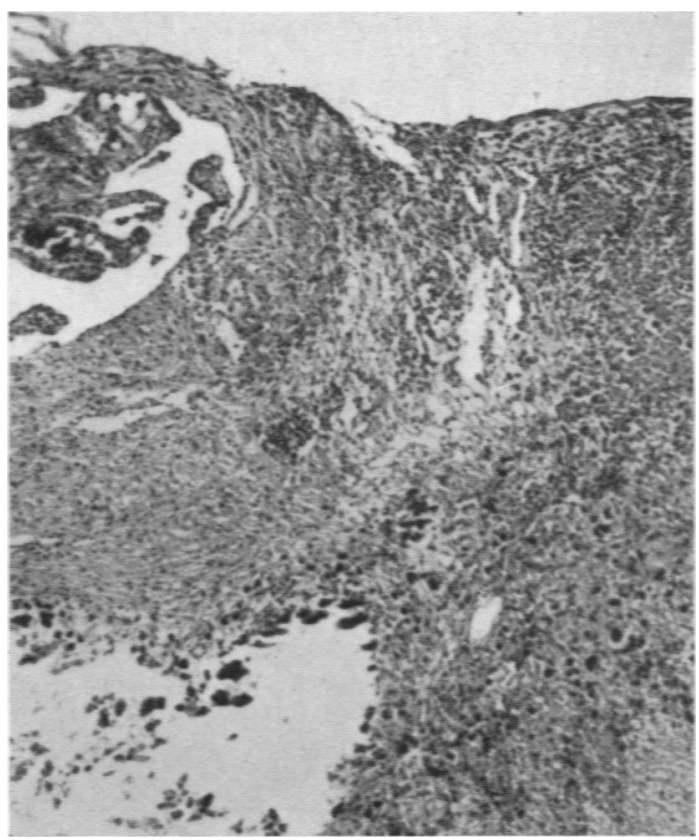

FiG. 5.-Wall of the lateral ventricle (haematoxylin and eosin $\times 65$ ) showing extensive necrosis and granular calcification close to the choroid plexus. 
by one of us (P.D.M.) Externally, the child showed marked generalized cedema, faint jaundice and extreme pallor. There was a purpuric generalized rash, most profuse on the face and scanty on the soles and palms. On the trunk there was an average of six lesions per $100 \mathrm{~cm}^{2}$., the individual haemorrhages varying from pin-point size to $3 \mathrm{~mm}$. diameter. The eyes appeared normal and there was no external evidence of hydrocephalus.

Internally, the fatty tissues were jaundiced and the body-wall oedematous. Petechiae were seen in the muscles, especially of the legs.

There was a very small amount of free fluid in the pleural cavities, but no pleural petechiae. The lungs (27 g.) were small and unexpanded. There was free fluid in the pericardium.

The chambers of the heart were dilated; the myocardium was pale.

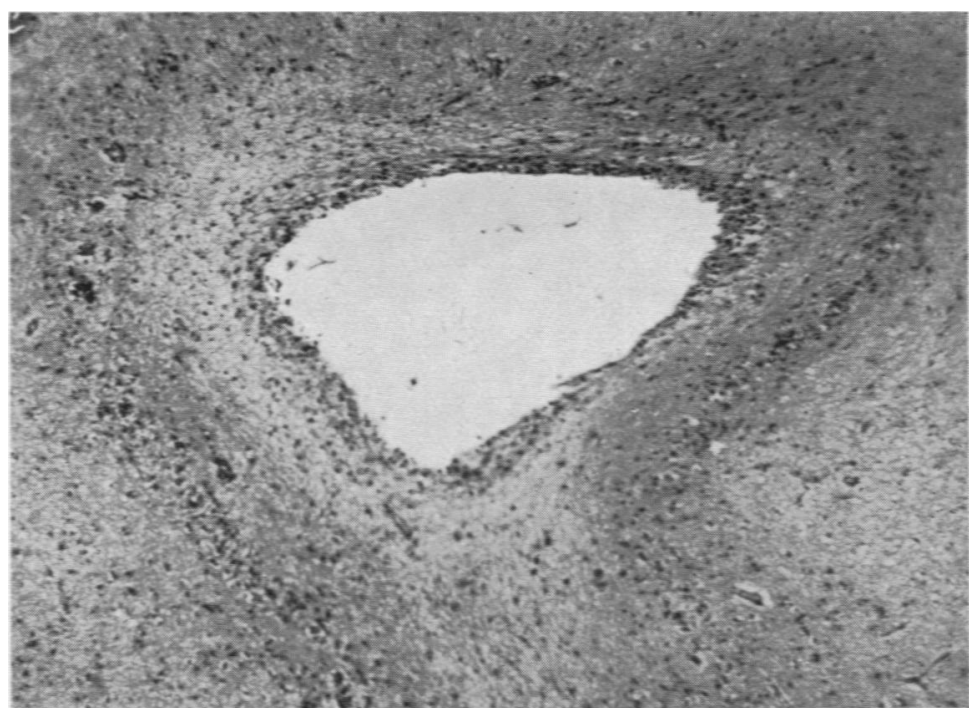

Fig. 6.-Aqueduct at the level of the inferior quadrigeminal body (haematoxylin and eosin $\times 55)$ showing gliosis.

There were no petechiae.

In the abdomen there was approximately $40 \mathrm{ml}$. of straw-coloured fluid.

Discrete and confluent petechiae were seen at the upper end of the oesophagus. Occasional mucosal and subserous petechiae were seen in the stomach and small intestine.

The colon was normal.

The liver $(160 \mathrm{~g}$.) was enlarged, pale and yellow.

The spleen (68 g.) was also enlarged, dark purple and firm. There was nothing of note in the endocrine glands.

The kidneys ( $44 \mathrm{~g}$.) were enlarged, with subcapsular petechiae, a smooth surface, the cortex intensely congested to within $1 \mathrm{~mm}$. of the surface and the medulla relatively pale. Nothing was noted in the urinary passages.

The skull was of normal size. The bones were normal. There was a small tear in the falx just above the tentorium, with a little blood clot in the posterior fossa. The brain had a normal surface configuration. There was no hydrocephalus. Scattered over the surface, and particularly within the sulci, were minute yellow, discoloured zones in the superficial cortex, nowhere more than 0.5 $\mathrm{mm}$. in depth, to which the leptomeninges were adherent. The lining of the lateral ventricles was granular and yellow, the zone of discoloration extending about 0.5 $\mathrm{mm}$. into the surrounding brain, which otherwise appeared normal. Sections across the brain-step and basal nuclei were normal. There was slight granularity of the floor of the fourth ventricle.

Histology. The portal areas of the liver (Fig. 7) were densely infiltrated with mononuclear cells, lymphocytes, plasma cells and occasional eosinophils, the infiltrate extending between compressed and distorted liver columns into the lobules. There was early fibrosis extending from the portal tracts. The sinusoids were widely dilated and islands of extramedullary erythropoiesis were frequent. Biliary plugs were present in the canaliculi, but the bile ducts were normal. Though no pseudocysts were seen, there were small groups of spherical or ovoid bodies, resembling free Toxoplasma, amongst the inflammatory cells. There was a marked excess of iron pigment.

In the spleen follicles were inconspicuous. The pulp was congested and densely packed with erythropoietic cells and mononuclear cells. Erythrophagocytosis was present. No pseudocysts or free Toxoplasma were seen. Much free iron was present.

The lungs were not aerated. There were scanty meconium granules. In the interstitial tissue, especially around the bronchi and blood vessels, there were occasional mononuclear cells. In the alveoli there were scattered mononuclear cells. In some of these and in the interstitial tissue parasites were seen singly and in groups (Fig. 8).

In the skeletal muscle of the calf there was diffuse mononuclear and lymphocytic infiltration, especially marked in perivascular areas, many capillaries having dense collars of cells. There was a moderate degree of oedema. Occasional areas of necrosis of muscle fibres with surrounding zones of inflammatory cells were seen. As well as small groups of free parasites, occasional large pseudocysts in parasitized fibres, without cellular reaction, were seen. Throughout both cortex and medulla of the kidney, but especially in the former, there was a dense infiltration of mononuclear cells, plasma cells and lymphocytes, with numerous foci of erythropoiesis. Areas of haemorrhage and necrosis were frequent. The glomeruli were normal, but the convoluted tubules were distorted and compressed by the interstitial cellular reaction. There was a similar cellular infiltration in the 


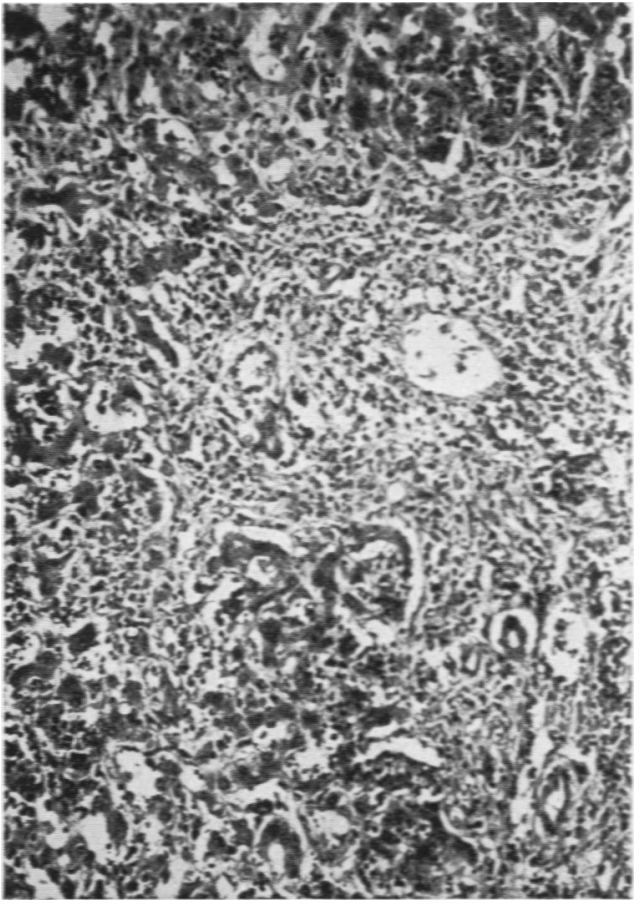

Fig. 7.-Liver (haematoxylin and $\operatorname{cosin} \times 100$ ), showing infiltration and fibrosis of portal tracts, with sinusoid erythropoiesis.

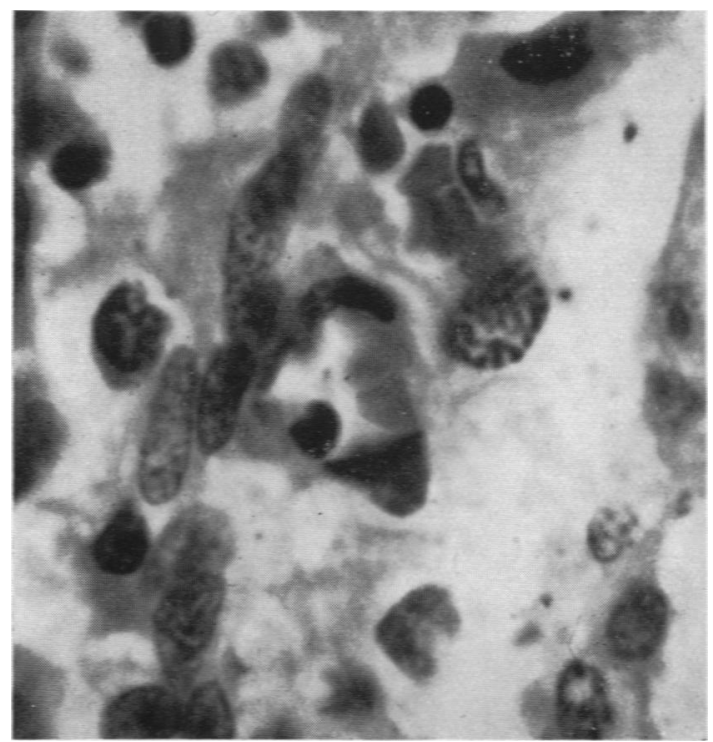

FiG. 8.- Lung (haematoxylin and cosin $\times 1,300$ ) showing intracellular mass of parasites in alveotar wall and nucleated red cells in capillaries.

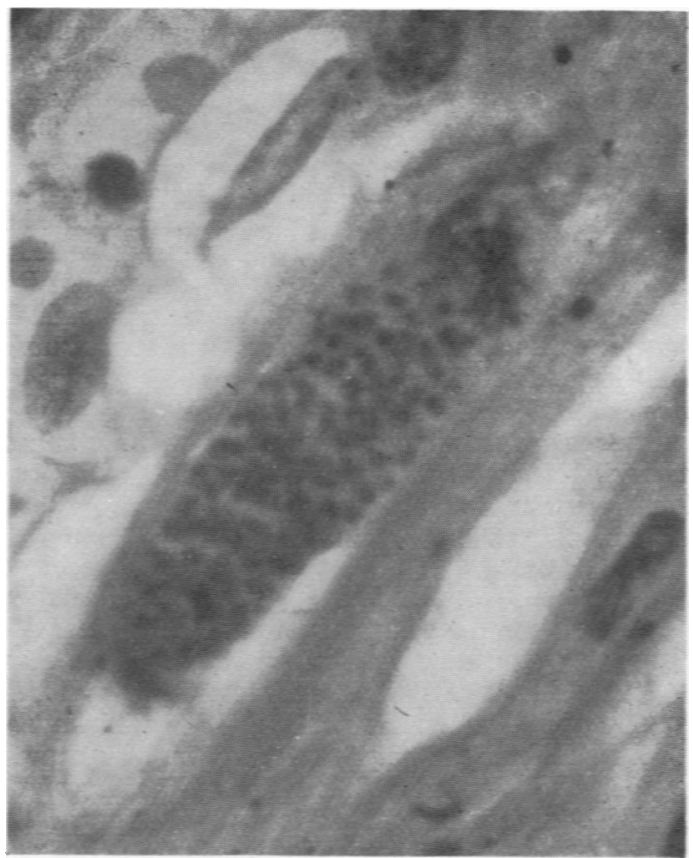

Fic. 9.- Heart (hsematoxylin and cosin $\times 1,800$ ) showing pseudocyst in muscle fibre without surrounding reaction.

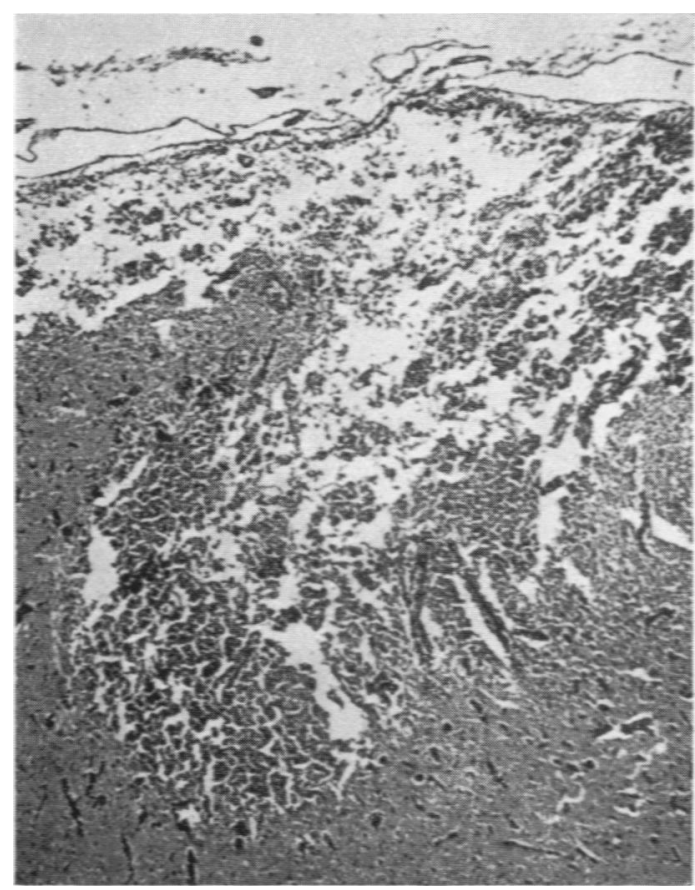

FiG. 10.- Brain (hnematoxylin and cosin $\times 36$ ) showing necrotic cortical lesion, prominent marginal capillaries and meningeal infiltration.

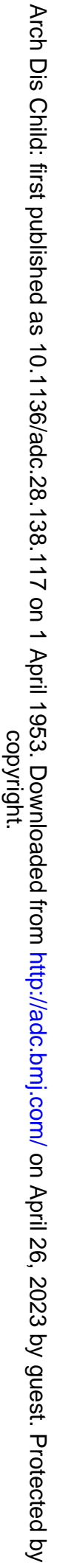


peripelvic connective tissue. Granules of iron pigment were conspicuous in the renal tubular epithelium. No definite free parasites were seen nor were pseudocysts noted.

The pattern of the pancreas was normal. The interlobular stroma was oedematous. Scattered throughout were numerous foci of erythropoiesis, lymphocytes, histiocytes and plasma cells. The peripancreatic areolar tissue showed similar diffuse infiltrations. No Toxoplasma were seen.

The bone marrow was extremely cellular containing a high proportion of erythroid cells. Platelet precursors were relatively scanty. Occasional small groups of Toxoplasma were seen.

In the heart oedema was marked with diffuse inflammatory infiltration and islands of erythropoiesis. Occasional muscle fibres contained pseudocysts, without surrounding reaction (Fig. 9).

Some of the villi of the placenta showed a moderate degree of oedema, with scanty large mononuclears and plasma cells. In the villi, both within mononuclear cells and lying freely, were Toxoplasma singly and in small clumps. When single, they were predominantly ovoid, the cytoplasm staining bluish-red with haematoxylin and eosin, the nuclear chromatin, usually towards one end of the organism, a darker blue. When in clumps, the nuclear chromatin showed as round blue areas, frequently surrounded by a pale zione, the cytoplasm being ill defined. Nucleated red cells were present within the capillaries of the villi.

The superficial cortical lesions noted macroscopically on the brain were areas of necrosis containing many compound granular corpuscles and much nuclear debris. At their margins there was a zone of prominent, dilated capillaries, with swollen endothelial cells and narrow cuffs of reticulum and plasma cells (Fig. 10). Similar cells were present throughout the marginal zone. In the most recent lesions, where necrosis was minimal and the cellular infiltration most dense, free Toxoplasma and small pseudocysts were seen, but in the older lesions calcification in minute granules made certain identification of the parasites difficult and sometimes impossible. The adherent overlying meninges were congested and infiltrated with plasma cells, lymphocytes, large mononuclear cells and occasional polymorphs, the infiltration extending for some distance over uninvolved cortex. Toxoplasma were seen in small numbers lying free in the subarachnoid space, and within mononuclear and capillary endothelial cells.

In the walls of the lateral ventricles there were extensive areas in which the ependyma was replaced by confluent areas of necrosis similar to those on the surface, profusely studded with dust-like particles of calcium. Between the necrotic areas the ependyma was broken up and covered with an organizing fibrillary membrane containing isolated inflammatory cells. Similar changes were present in the third ventricle, necrosis and calcification being most advanced close to the choroid plexus.

The aqueduct was patent throughout, but its lumen was slightly reduced by glial nodules which erupted through and isolated small groups of epen dymal cells.
Similar glial nodules, but no areas of necrosis, were seen in the floor of the fourth ventricle (Fig. 11).

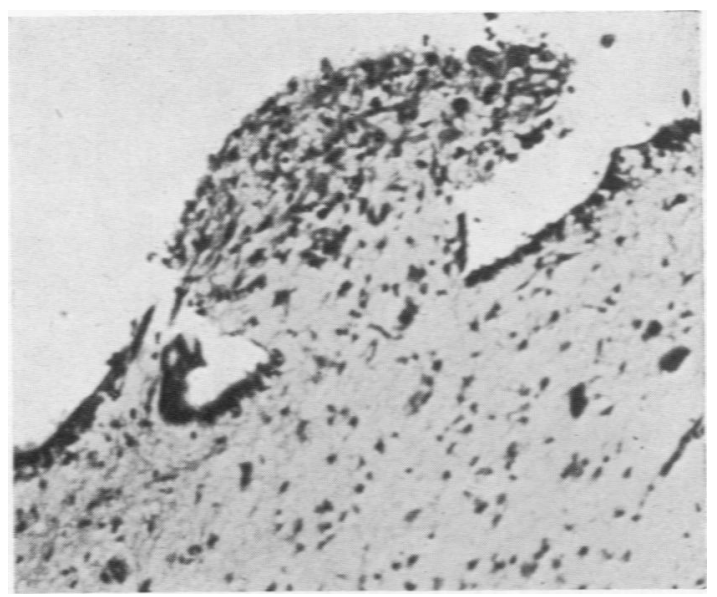

Fig. 11.-Brain (haematoxylin and eosin $\times 130$ ) showing glial nodule in floor of the fourth ventricle.

The deeper parts of the brain showed only scattered miliary granulomas and occasional pseudocysts, the latter devoid of surrounding reaction (Fig. 12).

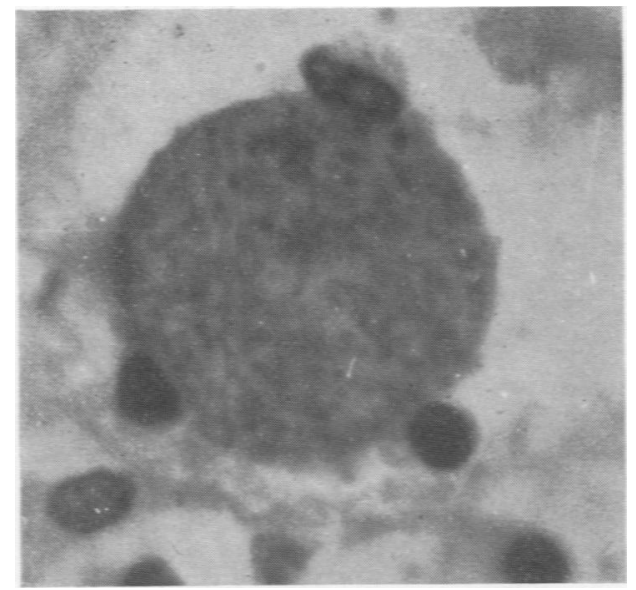

FIG. 12.-Irain (haematoxylin and $\operatorname{cosin} \times 1,700$ ) showing typical pseudocyst.

The eyes were not available for examination.

This case showed a close clinical resemblance to haemolytic disease of the newborn, but histological examination revealed widespread neural and extraneural infection by Toxoplasma. Serological examination of the mother's serum supported this diagnosis, and did not show evidence of iso-immunization. 


\section{Discussion}

We do not propose to discuss the commoner clinical features or the specific pathological lesions of congenital toxoplasmosis as these have been reviewed recently by Callahan, Russell and Smith (1946), Binkhorst (1948), Magnusson and Wahlgren (1948), Frenkel (1949), Wyllie and Fisher (1950) and Hart, Paulley, Rivers and Westlake (1951). There are, however, several points worthy of comment.

The rash was an arresting clinical feature of both our cases. Rashes have been mentioned in a number of the published cases, but not always described in detail. Callahan et al. described the rash in two of their cases as ecchymotic. Most of the others are described as petechial or purpuric, sometimes coming on after birth and noted especially in cases with jaundice. The usual distribution has been that seen in our cases. Several factors may play a part in their production. Hypoprothrombinaemia has been noted, especially with jaundice, so that liver damage may be a major factor, especially in those cases where the rash appears shortly after birth. A low platelet count has also been recorded in one or two cases and platelet deficiency due to toxic effects on the bone marrow has to be considered. We have seen a similar rash in congenital thrombocytopenic purpura. In our Case 1 there were 72,000 platelets per c.mm. on the day of birth, the bleeding and clotting times being normal. At 4 weeks old the platelet count was normal. In our Case 2, showing a similar rash, the bone marrow was very active, but platelet precursors were scanty. In the few previous reports a cellular marrow has been noted, but no comment made on platelet formation. It is possible that the skin lesions might also be produced by embolism during the parasitaemic stage, or by a local allergic reaction to the presence of Toxoplasma in capillary endothelial cells.

Congenital toxoplasmosis may closely resemble haemolytic disease of the newborn, as in Case 2, where the initial clinical diagnosis, based on the gross pallor, universal oedema and enlargement of liver and spleen, was hydrops foetalis. A similar diagnosis of erythroblastosis was made in three of the 18 cases reviewed by Callahan et al. (1946), in the case reported by Harwin and Angrist (1948) and in one of the cases reported by Magnusson and Wahlgren (1948).

In these cases and in other infants dying within a few days of birth (e.g. Pratt-Thomas and Cannon, 1946; Werthemann, 1948), extramedullary erythropoiesis of abnormal degree has been observed, usually associated with jaundice and enlargement of the liver and spleen. Though data regarding blood group incompatibility are not available, except in our Case 2 and in that reported by Smitt and Winblad (1948), it would seem more reasonable to regard this high incidence of abnormal erythropoiesis as due to infection by Toxoplasma rather than to the simultaneous occurrence of two diseases. It is well known that anaemia with extramedullary erythropoietic activity is a common result of severe infection in the young infant. Such a response would be expected more frequently in recent infection of the foetus during the parasitaemic stage ('acute toxoplasmosis' of Frenkel, 1949), rather than in the later phase when active disease is limited to the central nervous system ('subacute toxoplasmosis') and other organs are normal or show evidence of past infection only. A survey of published necropsy reports indicates that, in general, the greater degrees of extramedullary erythropoiesis are associated with evidence of severe generalized disease, changes in the central nervous system in some instances being relatively early, while in those with little or no abnormal extramedullary erythropoiesis, extraneural disease is overshadowed by severe involvement of the brain and cord.

Callahan et al. (1946) remark that there is, in most cases, no satisfactory explanation of jaundice occurring in congenital toxoplasmosis. In the liver, toxoplasmic granulomas have not been found, and free parasites noted only on very rare occasions, the main features, except in one case discussed below, being foci of erythropoiesis, haemosiderosis, inspissation of bile within the canaliculi, and occasionally a mononuclear periportal reaction. In cases of this type surviving beyond the immediate post-natal period (Zuelzer, 1944, cases 2 and 3; Cowen, Wolf and Paige, 1942; Paige, Cowen and Wolf, 1942; Magnusson and Wahlgren, 1948, case I; Smitt and Winblad, 1948) the clinical evidence has been compatible with hepatitis. Post-mortem studies in three such cases (Smitt and Winblad, 1948; Werthemann, 1948; Zuelzer, 1944) demonstrated hepatitis with definite fibrosis in two. Again, no specific lesions of toxoplasmosis were demonstrated. Our case 2, where the initial clinical diagnosis was hydrops foetalis, showed severe hepatitis with fibrosis at birth, and resembled case 11 of Magnusson and Wahlgren, a hydropic infant dying one minute after birth, where there was a well marked centrilobular hepatic necrosis.

The only regular findings in the enlarged spleens have been excessive haemopoietic activity and haemosiderosis. In the few instances where bone marrow has been sectioned haemopoietic activity has been normal or increased.

Sabin (1942) suggested that the jaundice might be due to a direct toxic effect of Toxoplasma on the liver 
cells. Such a mechanism is possible, but the evidence detailed above suggests that it may be due, at least in part, to rapid destruction of red cells and liver damage similar to that seen not uncommonly in haemolytic disease due to iso-immunization.

Observations on the placenta in toxoplasmosis are very scanty. In a majority of cases it is not mentioned: in a few it is reported as macroscopically normal, without further details being given. Lelong, Rossier, Alison, Le Tan Vinh, Desmonts, Boulard and Ribierre (1948) describe two cases; in one the infant weighed $2,550 \mathrm{~g}$. ( $5 \mathrm{lb} .9 \mathrm{oz}$.) and the placenta $650 \mathrm{~g}$. (1 lb. $7 \mathrm{oz}$.); in the other the weights were, respectively, $3,000 \mathrm{~g}$. (6 lb. $9 \mathrm{oz}$.) and $500 \mathrm{~g}$. (1 lb. $2 \mathrm{oz}$.), both within normal limits for the maturity of the infants. The placentas are not further described. In neither case is there any note of jaundice, hepatoor spleno-megaly or rash during the neonatal period. In the case described by Kean and Grocott (1948) the placenta was noted to be very grey, but unfortunately could not be further examined. The patient of Smitt and Winblad (1948), similar in many respects to our first case, weighed $2,460 \mathrm{~g}$. $(5 \mathrm{lb}$. $6 \mathrm{oz}$.) at birth, the placenta $880 \mathrm{~g}$. (1 lb. $15 \mathrm{oz}$.). Paige et al. (1942) describe a placenta, apparently grossly normal, in which microscopy showed only evidence of secondary pyogenic infection.

Mellgren, Alm and Kjessler (1952) have recently described a placenta in which there were areas of necrosis infiltrated with polymorphs, and showing early calcification. Bodies resembling Toxoplasma were seen, especially at the margins of the infarcts, and Toxoplasma were subsequently cultured from the vaginal discharges. Serological tests on the mother were positive. The moderately macerated, immature infant did not show any gross lesions at necropsy, and sections of the lungs did not reveal Toxoplasma.

In our case 1 the weight of the placenta was somewhat greater than the average for the weight and maturity of the infant, but in case 2 it was more than half the weight of the baby and had the grey appearance noted by Kean and Grocott (1948).

In both cases studied by us there was no evidence of a gross inflammatory reaction in the placenta, the changes being confined to slight cellular infiltration and oedema in case 2. Though bodies resembling Toxoplasma were infrequently seen in the placenta of case 2, they were devoid of tissue reaction and were probably derived from the foetal parasitaemia, rather than directly from the mother. Focal areas of necrosis similar to those described by Cowen and Wolf (1950) in the placentas of experimentally infected mice were not seen. If such lesions do occur during transmission of infection from mother to foetus it is quite possible that they may be un- identifiable by the time gross lesions have been produced in the infant. Werthemann (1948), in commenting on the absence of placental damage in cases of toxoplasmosis, says that a similar state of affairs exists in congenital malaria, where, though Plasmodia may be found in the placenta in large numbers, there is little evidence of tissue reaction.

It has been suggested that the malarial parasite may be able to gain access to the foetal circulation without structural damage to the placenta. An alternative suggestion is that small haemorrhages in the placenta during malarial rigors or during labour may occur. We think, therefore, that it is improbable that structural changes in the placenta directly due to toxoplasmosis would account for the considerable enlargement of the placenta in our case 2 or for the slighter enlargement in our case 1 and in the case of Smitt and Winblad (1948). It appears more probable that the increase in placental size was due to oedema, analogous to that occurring in hydrops foetalis.

\section{Summary}

The clinical, morbid anatomical and histological details of two cases of congenital toxoplasmosis presenting somewhat unusual features at birth are described. Toxoplasma were identified in both cases. The significance of some of the extraneural lesions is discussed, and the absence of specific changes in the placentas noted.

Our thanks are due to Professor T. N. A. Jeffcoate and $\mathrm{Mr}$. C. H. Walsh for permission to report these cases from their units, to Professor N. B. Capon for his comments on case 1, to Mr. J. A. McCann for the ophthalmological report on case 1 , to Dr. A. S. Whitehead for drawing our attention to the radiograph of case 2, to Dr. R. E. Rewell for details of the necropsy on case 1, and to Dr. A. Macdonald for the serological results.

\section{REFERENCES}

Binkhorst, C. D. (1948). Toxoplasmosis. Leiden.

Callahan, W. P., Russeli, W. O. and Smith, M. G. (1946). Medicine, Baltimore, 25, 343.

Cowen, D. and Wolf, A. (1950). J. exp. Med., 92403. and Paige, B. H. (1942). Arch. Neurol. Psychiat., Chicago, 48. 689 .

Frenkel, J. K. (1949). J. Amer. med. Ass., 140. 369.

Hart, E. W., Paulley, J. W., Rivers, J. S. and Westlake, E. K. (1951). Arch. Midd. Hosp., 1, 26.

Harwin, M. and Angrist, A. (1948). Arch. Pedial., 65. 124.

Kean, B. H and Grocott, R. G. (1948). J. Amer. med. Ass., 136. 104.

Lelong M. Rossiet, A. Alison, F., Le Tan Vinh, Desmonts, G. Boulard, - and Ribierre, -. (1948). Arch. franc. Pediat., $5,113$.

Magnusson, J. H. and Wahlgren, F. (1948). Acta. path. microbiol. scand., 25, 215.

Mellgren, J., Alm, L. and Kjessler, A. (1952). Ibid., 30, 59.

Paige, B. H. Cowen, D. and Wolf, A. (1942). Amer. J. Dis. Child., 63, 474.

Pratt-Thomas, H. R. and Cannon, W. M. (1946). Amer. J. Path., 22, 779 .

Sabin A. B. (1942). Advanc. Pediat., 1, 1.

Sabin, A. B. (1942). Advanc. Pediat., 1, 1. microbiol. scand., 25. 585.

Werthemann, A. (1948). Ann. paediat., Basel, 171, 187.

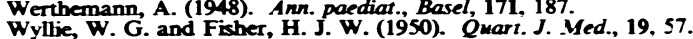

Zuelzer, W. W. (1944). Arch. Path., Chicago, 38, 1. 